\title{
BMJ Open Understanding trends in blood pressure and their associations with body mass index in Chinese children, from 1985 to 2010: a cross-sectional observational study
}

\author{
Bin Dong, ${ }^{1,2}$ Zhiqiang Wang, ${ }^{1,2}$ Yi Song, ${ }^{1}$ Hai-Jun Wang, ${ }^{1}$ Jun $\mathrm{Ma}^{1}$
}

To cite: Dong B, Wang Z, Song $Y$, et al. Understanding trends in blood pressure and their associations with body mass index in Chinese children, from 1985 to 2010: a cross-sectional observational study. BMJ Open 2015;5:e009050. doi:10.1136/bmjopen-2015009050

- Prepublication history and additional material is available. To view please visit the journal (http://dx.doi.org/ 10.1136/bmjopen-2015009050).

Received 12 June 2015 Revised 3 August 2015 Accepted 13 August 2015

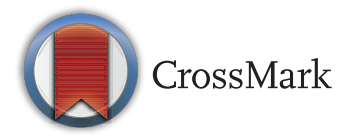

${ }^{1}$ Institute of Child and Adolescent Health, School of Public Health, Peking University Health Science Center, Beijing, China ${ }^{2}$ Centre for Chronic Disease, School of Medicine, The University of Queensland, Brisbane, Queensland, Australia

\section{Correspondence to}

Dr Jun Ma;

majunt@bjmu.edu.cn and

Dr Hai-Jun Wang;

whjun1@bjmu.edu.cn

\section{ABSTRACT}

Objective: Understanding trends in blood pressure (BP) in childhood is crucial to addressing and reducing the burden of adulthood hypertension and associated mortality in the future. In view of growing obesity in Chinese children, we sought to investigate the trends in $\mathrm{BP}$ and the influence of body mass index (BMI) on them.

Design, setting and participants: We included 1010153 children aged 8-17 years, with completed records from a large national successive cross-sectional survey, the Chinese National Survey on Students' Constitution and Health, between 1985 and 2010.

Main outcome measurements: BP was measured according to the recommendation of the National High Blood Pressure Education Program Working Group, and the elevated BP was based on sex-, age- and heightspecific 95th centile of the recommendation.

Results: The adjusted mean systolic BP in boys and girls decreased by 3.9 and $5.6 \mathrm{~mm} \mathrm{Hg}$ between 1985 and 2005, and increased by 1.3 and $1.0 \mathrm{~mm} \mathrm{Hg}$ between 2005 and 2010, respectively. Corresponding adjusted prevalence of elevated systolic BP in boys and girls declined from $5.1 \%$ and $5.5 \%$ to $3.5 \%$ and $2.5 \%$ between 1985 and 2005, and increased to $4.9 \%$ and $3.5 \%$ in 2010 , respectively. Adjusted mean BMI of boys and girls in 2010 was 2.0 and $1.2 \mathrm{~kg} / \mathrm{m}^{2}$ higher than those in 1985, respectively. The prevalence of obesity rose from $0 \%$ to $3.4 \%$ in boys and $0.9 \%$ in girls.

Further adjusting for BMI did not change these trends in systolic BP. A similar pattern was also observed in diastolic BP.

Conclusions: After declining for 20 years, BP levels in Chinese children started to climb upwards. These trends in BP cannot be fully explained by BMI. The investigation of other determinants of BP may provide additional opportunity to curb the current upward $\mathrm{BP}$ trend in Chinese children.

\section{INTRODUCTION}

Hypertension is one of the leading contributors to cardiovascular disease mortality,

\section{Strengths and limitations of this study}

- Successive national surveys between 1985 and 2010, with large population samples of Chinese children, were investigated.

- The consistent stratified cluster sampling procedure and methods of measurement could contribute to the comparability of the data of different years.

- The prevalence of elevated blood pressure may be overestimated by recording blood pressure based on three measurements in a single visit.

- Some risk factors that were not measured in these surveys may also contribute to the trends in blood pressure.

causing more than seven million deaths each year worldwide. ${ }^{1}$ Although hypertension was once considered to be a rare condition in children, ${ }^{2}$ it has become clear that elevated blood pressure (BP) is a life course problem that can become evident in childhood and can be progressive throughout childhood into adulthood. ${ }^{3}$ Furthermore, children with elevated BP also have an increased risk of end-organ damage, such as ventricular hypertrophy and increased carotid intima-media thickness. $^{4}$

Because of the strong association between obesity, defined according to body mass index (BMI) levels, and elevated BP, the dramatic rise in the prevalence of obesity over the past three decades is expected to lead to a parallel rise in BP in children. ${ }^{5}$ However, studies in different countries demonstrated that trends in childhood BP do not necessarily parallel changes in BMI, ${ }^{6-9}$ and mean $\mathrm{BP}$, as well as prevalence of elevated BP, even declined during a period when BMI was increasing. ${ }^{10}{ }^{11}$ Prevalence of obesity in Chinese children has increased in the past 
30 years along with the rapid economic growth in the country. ${ }^{12}$ However, the secular trends in BP among Chinese children remain unclear. One available study based on a small sample reported the upward trends in BP between 1991 and 2004. ${ }^{13}$ However, that study did not consider the secular increases in height when the trends in BP were evaluated, and part of the observed increase in $\mathrm{BP}$ over time might relate to a concomitant increase in children's height. ${ }^{14}{ }^{15} \mathrm{~A}$ better understanding of childhood BP trends and the impact of the increasing BMI on BP trends may provide opportunities to reduce the burden of adulthood hypertension and associated mortality in the future.

On the basis of national surveys between 1985 and 2010 among more than one million school-age children, we traced secular changes in BP, and further investigate the potential contribution of BMI on $\mathrm{BP}$ trends in Chinese children over the past three decades.

\section{METHODS}

\section{Study design and subjects}

Data were obtained from the 1985, 1995, 2000, 2005 and 2010 cycles of the Chinese National Survey on Students' Constitution and Health (CNSSCH), a large national successive cross-sectional survey designed to investigate health status in Chinese school-age children. The sampling procedures of CNSSCH have been published previously in detail. ${ }^{12}$ In brief, these surveys used the same multistage sampling method to select students from each of the mainland provinces. Each province was classified into two area groups (urban and rural) according to residential regions, which were further classified into sex- and age-specific subgroups. In each subgroup, equal numbers of participants were selected from primary and secondary schools. Thus, an equal size of sample was obtained in each. To ensure the accuracy of the comparison among surveys conducted in different years, not only were the participants drawn from the same urban and rural areas, but more than $85 \%$ of the sample schools remained the same in these surveys.

In this study, only participants of Han nationality were included, who accounted for approximately $92 \%$ of the total Chinese population, and all participants had lived for at least 1 year in the local area. In addition, Tibet, where Han ethnicity is in the minority, and Hainan and Chongqing, which were set up after 1985, were excluded in this study. Thus, only 28 provinces and municipalities were included. Of 1016572 participants aged 8-17 years, we excluded 6419 participants $(0.6 \%)$ with missing data or extreme height, weight and BP values ( $>5$ SDs from the survey year; sex- and age-specific mean). Thus, a total of 1010153 participants with complete records on age, sex, height, weight and BPs, were included in analyses. The distribution of sex, as well as urban and rural area, was quite similar throughout the surveys and approximately equalled 1:1 in each survey year (see online supplementary table S1).
These surveys were conducted according to the guidelines laid down in the Declaration of Helsinki and approved by six ministries of China, including the Ministry of Education, General Administration of Sport, Ministry of Health, State Ethnic Affairs Commission, Ministry of Science and Technology, and Ministry of Finance. Informed consent was obtained from parents and from students. The project of analysing the survey data was approved by the Medical Research Ethics Committee of the University of Queensland (\#2011001199).

\section{Measurements}

Anthropometric measurements were performed according to the same protocol at all survey sites. ${ }^{12}$ Students were asked to wear light clothes only, and to stand straight without shoes. Height was measured using a wall-mounted stadiometer to the nearest $0.1 \mathrm{~cm}$, and weight was measured with a scale to the nearest $0.1 \mathrm{~kg}$. Both height and weight were measured twice, and the mean values were recorded. BMI was calculated with the value of weight divided by height squared $\left(\mathrm{kg} / \mathrm{m}^{2}\right)$, and was categorised as thin, normal weight, overweight or obese, according to the sex- and age-specific references suggested by Cole et al. ${ }^{16}{ }^{17}$ Sex- and age-specific BMI z-scores were calculated according to the Centers of Disease Control and Prevention (CDC) growth charts. ${ }^{18}$

$\mathrm{BP}$ was measured according to the recommendation of the National High Blood Pressure Education Program (NHBPEP) Working Group in Children and Adolescents, ${ }^{19}$ using an auscultation mercury sphygmomanometer with an appropriate cuff for children. Cuff sizes were selected according to the NHBPEP working group, which stipulates that the cuff bladder width should cover $50 \%$ to $75 \%$ of the mid-arm circumference. $\mathrm{BP}$ was measured in the sitting position and on the right arm after a rest of at least 5 min. Systolic BP was defined as the onset of 'tapping' Korotkoff sounds, and diastolic BP was defined as the fifth Korotkoff sound. An average of three BP measurements at a single visit was calculated for each child. Elevated systolic and diastolic BP was defined as systolic and diastolic BP $\geq$ the referent age-, sex- and height-specific 95th centile, respectively. ${ }^{19}$ Sexand age-specific percentiles of height were derived from the CDC growth charts as suggested by the NHBPEP working group. ${ }^{18}{ }^{19} \mathrm{BP}$ was also converted into z-score by using formulas suggested by the NHBPEP working group. ${ }^{19}$ Since diastolic BP was defined by the fourth or fifth Korotkoff sound based on age between 1985 and 1995, only the data between 2000 and 2010 were analysed for diastolic BP.

Throughout all surveys, the measurement instruments were calibrated before use and all technicians were required to pass the standard measurement test after a rigorous 1 week training course. In each survey year, all measurements were conducted by the same team of technicians at each site. 


\section{Statistical analysis}

For the analyses of the trends in levels of $\mathrm{BP}$ and prevalence of elevated BP, the multivariate linear and logistic regression models that included survey year as the categorical predictor were used, respectively. Because age and height, and the distribution of province and urban/ rural area may influence the BP levels among different surveys, we included all of these characteristics into the model when trends in mean BPs were assessed, and controlled all of these characteristics, except height, when the trends in prevalence of elevated BP were evaluated. Age, province and urban/rural area were also controlled when trend in BMI was assessed. To investigate the influence of BMI on trends in BP between 1985 and 2010, we used linear regression to estimate the mean $\mathrm{BP}$ in every survey year after further adjusting for BMI and BMI-by-survey year interaction. The strength of the association between BP and BMI was examined with BP as the dependent variable and with survey year, BMI category, age, height, province, area and survey year-by-BMI category interaction term as the independent variables. A negative coefficient for the interaction term suggests a weaker association between BMI and BP in that survey year, while a positive coefficient suggests a stronger association between BMI and BP. These results were performed by sex and age group graphically. All analyses were performed using Stata V.13 software (StataCorp, College Station, Texas, USA).

\section{RESULTS}

The characteristics of the study population in five surveys are shown in table 1 . There were obvious increases in height and BMI between 1985 and 2010. However, the BP levels decreased between 1985 and 2005, and rose between 2005 and 2010, in both sexes.

Table 2 presents the trends in systolic BP level over a 25-year period after adjusting for height and other confounders. This adjustment did not change the trends in systolic BP. The mean systolic BP decreased by $3.9 \mathrm{~mm} \mathrm{Hg}$ in boys and $5.6 \mathrm{~mm} \mathrm{Hg}$ in girls between 1985 and 2005, and followed by an increase of 1.4 and $1.0 \mathrm{~mm} \mathrm{Hg}$ in boys and girls between 2005 and 2010, respectively. These trends in $\mathrm{BP}$ were also observed when BPs were converted into sex-, age- and heightspecific z-scores. The prevalence of elevated systolic BP revealed a $31 \%$ and $55 \%$ relative decrease in boys and girls in 2005, respectively, compared with the corresponding prevalence in 1985 (5.1\% in boys and 5.5\% in girls). However, in 2010, the corresponding prevalence ascended to $4.9 \%$ in boys and $3.5 \%$ in girls, approximately $43 \%$ and $40 \%$ relative increase compared with those in 2005 in boys and girls, respectively. Similar patterns were found in most sex and age groups. Mirroring the trends in systolic BP, mean diastolic BP, diastolic BP z-score and the prevalence of elevated diastolic BP dropped between 2000 and 2005 and rose between 2005 and 2010, though the amplitude of the trends was

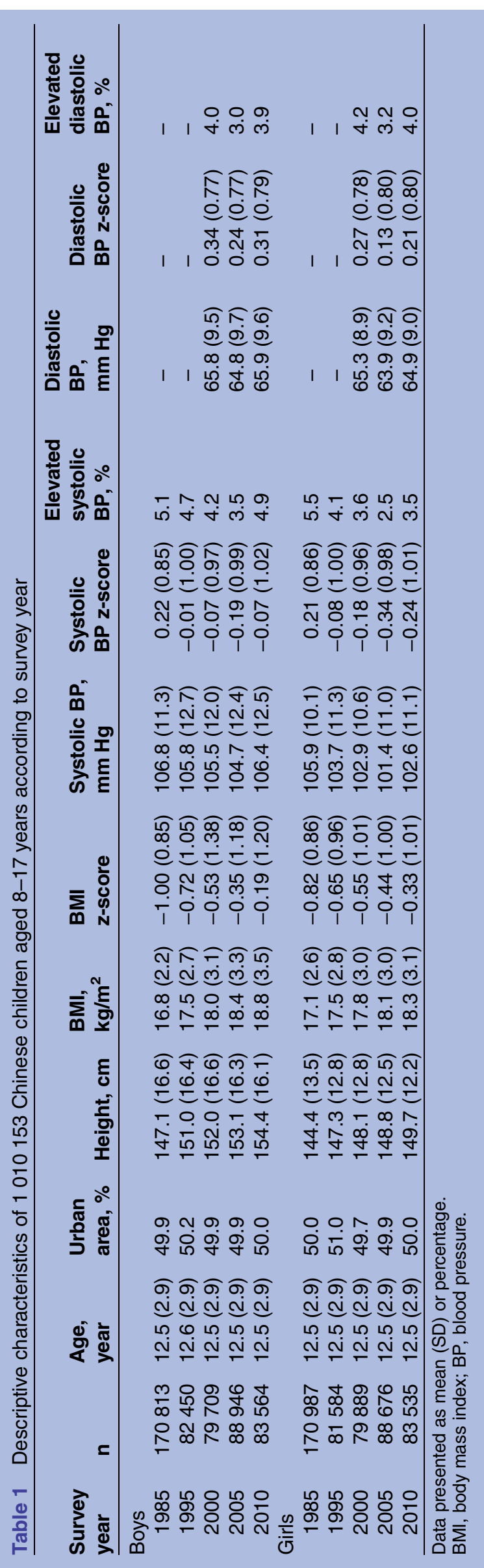


Table 2 Trends in adjusted mean systolic BP, systolic BP z-score and prevalence of elevated systolic BP in Chinese children aged 8-17 years between 1985 and 2010

\begin{tabular}{|c|c|c|c|c|c|c|c|}
\hline \multirow[b]{2}{*}{ Outcome } & \multirow{2}{*}{$\begin{array}{l}\text { Age group, } \\
\text { year }\end{array}$} & \multirow[b]{2}{*}{$\mathbf{n}$} & \multicolumn{5}{|l|}{ Survey year } \\
\hline & & & 1985 & 1995 & 2000 & 2005 & 2010 \\
\hline \multicolumn{8}{|c|}{ Adjusted systolic BP, $\mathrm{mm} \mathrm{Hg}^{*}$} \\
\hline \multirow[t]{4}{*}{ Boys } & $8-10$ & 150791 & $100.7(0.04)$ & $98.2(0.1)$ & $98.8(0.1)$ & $97.1(0.1)$ & $98.5(0.1)$ \\
\hline & $11-13$ & 151889 & $106.1(0.05)$ & $103.8(0.1)$ & $103.2(0.1)$ & $102.1(0.1)$ & $103.6(0.1)$ \\
\hline & $14-17$ & 202802 & $114.9(0.04)$ & $112.6(0.1)$ & $111.1(0.1)$ & $110.5(0.1)$ & $111.6(0.1)$ \\
\hline & Total & 505482 & $107.9(0.03)$ & $105.7(0.04)$ & $105.1(0.04)$ & $104.0(0.03)$ & $105.4(0.04)$ \\
\hline \multirow[t]{4}{*}{ Girls } & $8-10$ & 151017 & $100.9(0.04)$ & $97.9(0.1)$ & $97.9(0.1)$ & $95.7(0.1)$ & $97.2(0.1)$ \\
\hline & $11-13$ & 151633 & $106.8(0.05)$ & $104.2(0.1)$ & $103.1(0.1)$ & $101.2(0.1)$ & $102.4(0.1)$ \\
\hline & $14-17$ & 202021 & $110.6(0.04)$ & $107.6(0.1)$ & $105.8(0.1)$ & $104.8(0.1)$ & $105.2(0.1)$ \\
\hline & Total & 504671 & $106.6(0.02)$ & $103.7(0.03)$ & $102.6(0.03)$ & $101.0(0.03)$ & $102.0(0.03)$ \\
\hline \multicolumn{8}{|c|}{ Adjusted systolic BP z-score† } \\
\hline \multirow[t]{4}{*}{ Boys } & $8-10$ & 150791 & $0.25(0.004)$ & $-0.02(0.006)$ & $0.02(0.006)$ & $-0.15(0.005)$ & $-0.04(0.006)$ \\
\hline & $11-13$ & 151889 & $0.16(0.004)$ & $-0.04(0.006)$ & $-0.09(0.006)$ & $-0.19(0.006)$ & $-0.04(0.006)$ \\
\hline & $14-17$ & 202802 & $0.24(0.004)$ & $0.01(0.005)$ & $-0.14(0.006)$ & $-0.21(0.005)$ & $-0.11(0.005)$ \\
\hline & Total & 505482 & $0.22(0.002)$ & $-0.01(0.003)$ & $-0.08(0.003)$ & $-0.18(0.003)$ & $-0.07(0.003)$ \\
\hline \multirow[t]{4}{*}{ Girls } & $8-10$ & 151017 & $0.22(0.004)$ & $-0.07(0.006)$ & $-0.06(0.006)$ & $-0.28(0.005)$ & $-0.13(0.006)$ \\
\hline & $11-13$ & 151633 & $0.24(0.004)$ & $0.01(0.006)$ & $-0.09(0.006)$ & $-0.27(0.006)$ & $-0.15(0.006)$ \\
\hline & $14-17$ & 202021 & $0.16(0.004)$ & $-0.15(0.005)$ & $-0.33(0.005)$ & $-0.43(0.005)$ & $-0.40(0.005)$ \\
\hline & Total & 504671 & $0.20(0.002)$ & $-0.08(0.003)$ & $-0.18(0.003)$ & $-0.34(0.003)$ & $-0.25(0.003)$ \\
\hline \multicolumn{8}{|c|}{ Adjusted elevated systolic BP, \% } \\
\hline \multirow{4}{*}{ Boys } & $8-10$ & 150791 & $3.6(0.1)$ & $3.2(0.1)$ & $4.6(0.1)$ & $3.7(0.1)$ & $5.7(0.1)$ \\
\hline & $11-13$ & 151889 & $3.6(0.1)$ & $3.8(0.1)$ & $3.8(0.1)$ & $3.1(0.1)$ & $4.8(0.1)$ \\
\hline & $14-17$ & 202802 & $7.4(0.1)$ & $6.6(0.1)$ & $4.2(0.1)$ & $3.5(0.1)$ & $4.4(0.1)$ \\
\hline & Total & 505482 & $5.1(0.1)$ & $4.7(0.1)$ & $4.2(0.1)$ & $3.5(0.1)$ & $4.9(0.1)$ \\
\hline \multirow[t]{4}{*}{ Girls } & $8-10$ & 151017 & $4.2(0.1)$ & $3.5(0.1)$ & $4.4(0.1)$ & $3.4(0.1)$ & $5.2(0.1)$ \\
\hline & $11-13$ & 151633 & $5.8(0.1)$ & $4.6(0.1)$ & $4.3(0.1)$ & $2.6(0.1)$ & $3.7(0.1)$ \\
\hline & $14-17$ & 202021 & $6.2(0.1)$ & $4.2(0.1)$ & $2.5(0.1)$ & $1.7(0.1)$ & $2.1(0.1)$ \\
\hline & Total & 504671 & $5.5(0.1)$ & $4.1(0.1)$ & $3.6(0.1)$ & $2.5(0.1)$ & $3.5(0.1)$ \\
\hline
\end{tabular}

weaker than that of systolic BP (see online supplementary table S2).

As shown in table 3, BMI increased markedly across the consecutive 25-year periods in both sexes. The adjusted mean BMI in 2010 was increased by 2.1 and $1.3 \mathrm{~kg} / \mathrm{m}^{2}$ in boys and girls, respectively, higher than that in 1985. Meanwhile, the prevalence of overweight and obesity in boys increased dramatically, rising from

Table 3 Trends in adjusted mean BMI, BMI z-score and BMI categories in Chinese children aged 8-17 years between 1985 and 2010

\begin{tabular}{|c|c|c|c|c|c|c|}
\hline \multirow[b]{2}{*}{ Survey year } & \multirow[b]{2}{*}{ Adjusted BMl, $\mathrm{kg} / \mathrm{m}^{2 \star}$} & \multirow[b]{2}{*}{ Adjusted BMI z-score } & \multicolumn{4}{|c|}{ BMI category, \% } \\
\hline & & & Thin & Normal weight & Overweight & Obesity \\
\hline \multicolumn{7}{|l|}{ Boys } \\
\hline 1985 & $16.8(0.01)$ & $-0.99(0.003)$ & 31.3 & 68.4 & 0.4 & 0.0 \\
\hline 1995 & $17.4(0.01)$ & $-0.73(0.004)$ & 24.8 & 70.9 & 4.0 & 0.4 \\
\hline 2000 & $17.9(0.01)$ & $-0.56(0.004)$ & 22.2 & 69.3 & 7.1 & 1.4 \\
\hline 2005 & $18.4(0.01)$ & $-0.35(0.004)$ & 18.9 & 68.7 & 10.1 & 2.3 \\
\hline 2010 & $18.9(0.01)$ & $-0.18(0.004)$ & 15.8 & 68.2 & 12.6 & 3.4 \\
\hline \multicolumn{7}{|l|}{ Girls } \\
\hline 1985 & $17.1(0.01)$ & $-0.81(0.002)$ & 34.2 & 65.2 & 0.7 & 0.0 \\
\hline 1995 & $17.5(0.01)$ & $-0.67(0.003)$ & 29.1 & 68.0 & 2.8 & 0.1 \\
\hline 2000 & $17.8(0.01)$ & $-0.57(0.003)$ & 27.1 & 67.9 & 4.6 & 0.4 \\
\hline 2005 & $18.1(0.01)$ & $-0.44(0.003)$ & 23.6 & 69.8 & 6.0 & 0.6 \\
\hline 2010 & $18.4(0.01)$ & $-0.33(0.003)$ & 20.7 & 70.8 & 7.6 & 0.9 \\
\hline
\end{tabular}


Boys

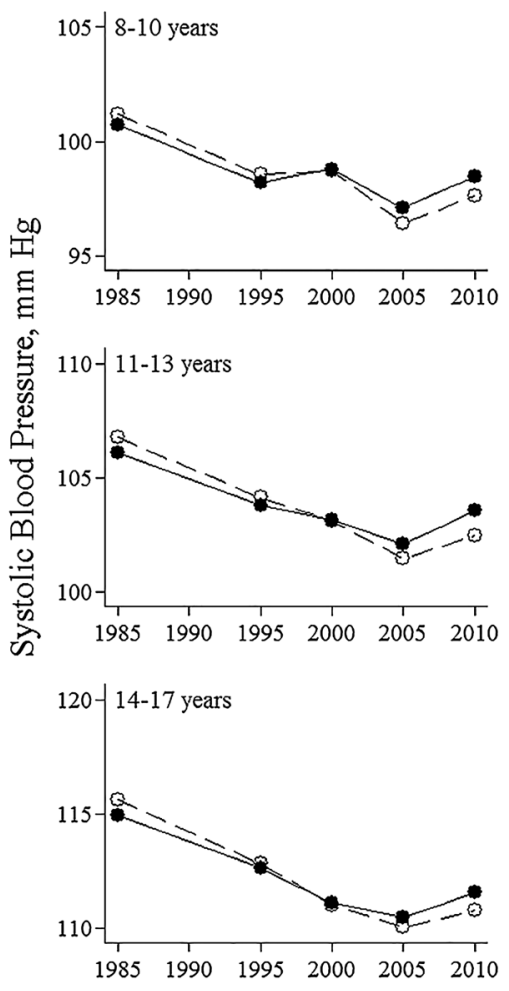

Girls
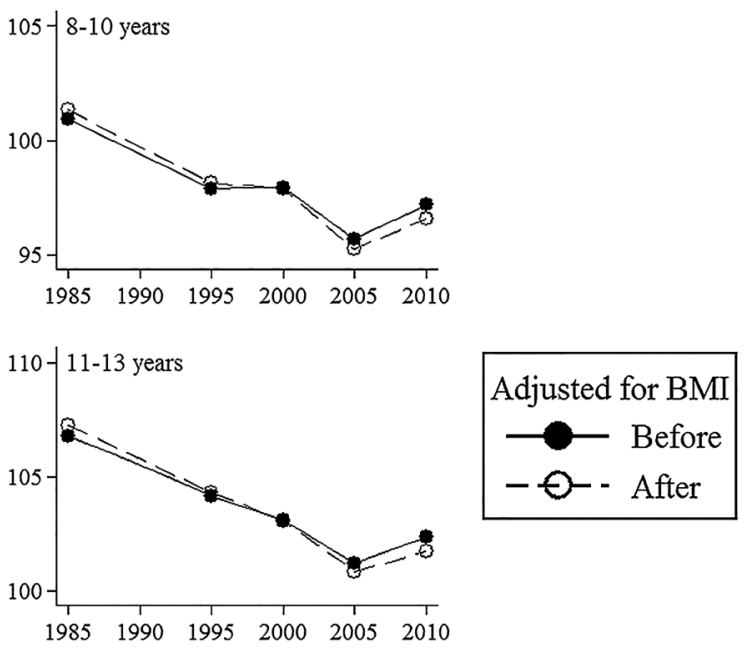

Survey Year

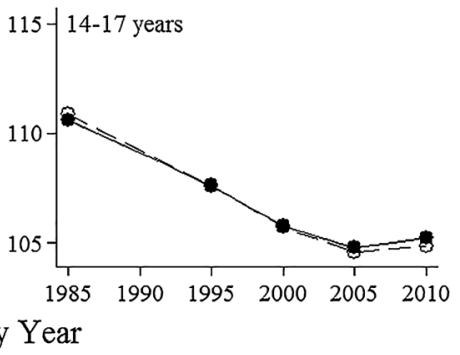

Figure 1 Adjusted mean systolic blood pressure in Chinese children aged 8-17 years between 1985 and 2010, before and after controlling for BMI. BMI, body mass index; solid lines represent the mean systolic blood pressures adjusted for age, height, province and urban/rural area; dashed lines represent the mean systolic blood pressures further adjusted for BMI and BMI-by-survey year interaction.

$0.4 \%$ to $12.6 \%$ in overweight and $0 \%$ to $3.4 \%$ in obesity. Similar trends were also observed in girls, but to a lower degree, rising from $0.7 \%$ to $7.6 \%$ in overweight and $0.0 \%$ to $0.9 \%$ in obesity.

Additional controlling for BMI did not substantially alter the trends in BP over the five surveys in both sexes (figure 1). This adjustment led to an increase in systolic $\mathrm{BP}$ in 1985 and 1995, ranging from 0.1 to $0.7 \mathrm{~mm} \mathrm{Hg}$, and a decrease in 2005 and 2010, ranging from -1.1 to $-0.2 \mathrm{~mm} \mathrm{Hg}$. In terms of trends in diastolic BP, the additional adjustment of BMI resulted in a slight variation, ranging from -0.2 to $0.2 \mathrm{~mm} \mathrm{Hg}$, depending on different sex and age groups (see online supplementary tables S3 and S4).

As presented in figure 2, in both sexes, systolic BP was significantly positively associated with BMI. Mirroring the trend in BP, the mean systolic BP tended to be high in 1985 and 1995, and low in 2005, across the BMI categories. Additionally, the strength (ie, slope) of the association between systolic BP and BMI varied slightly over 25 years. Survey year-by-BMI category interaction was also investigated in different sexand age-specific models, with the coefficients ranging from -3.65 to $2.55 \mathrm{~mm} \mathrm{Hg}$ in boys and -7.52 to $2.88 \mathrm{~mm} \mathrm{Hg}$ in girls, depending on various survey years and BMI categories. The trends in mean diastolic BP were similar to those in systolic BP (see online supplementary tables S5 and S6). No survey year-by-BMI category interaction term was significantly associated with diastolic BP in boys, except obese boys in 2005, with the coefficient of 1.44. Corresponding coefficients in girls ranged from 0.18 to $3.48 \mathrm{~mm} \mathrm{Hg}$ depending on various survey years and BMI categories.

\section{DISCUSSION}

Despite the steady increase in BMI among Chinese children, the BP levels did not parallel the changes in BMI. Mean BPs and prevalence of elevated BP both declined between 1985 and 2005, followed by an increase between 2005 and 2010. Controlling for height, BMI and other covariates did not change these trends in BP. Additionally, a similar trend was also observed in various sex and age groups. This rising BP trend in recent years could have essential public health importance.

Chiolero et $a l^{14}$ reviewed the trends in childhood elevated $\mathrm{BP}$ and found little evidence that $\mathrm{BP}$ has increased during the past few decades, despite the concomitant epidemic of obesity. Recent analyses of secular trends in BP among children in different countries have 
Boys

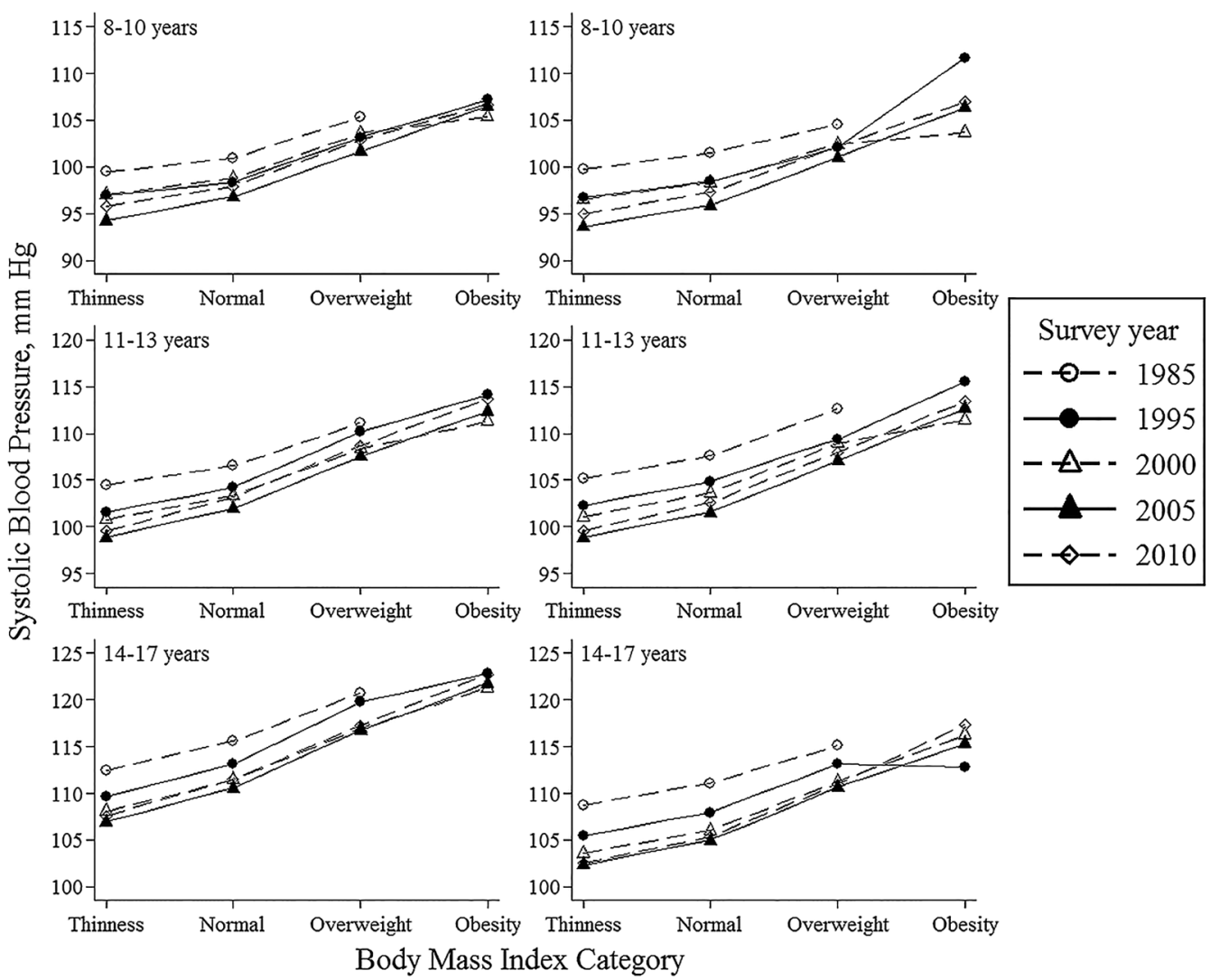

Figure 2 Adjusted mean systolic blood pressure according to the body mass index category in Chinese children aged 817 years between 1985 and 2010. Mean systolic blood pressures were adjusted for age, height, province, urban/rural area and body mass index category-by-survey year interaction.

demonstrated that BP levels have either increased, ${ }^{8} 20$ decreased ${ }^{10}{ }^{11}$ or not obviously changed over the past four decades. ${ }^{6}$ The lack of controlling for height complicates the interpretation of some results. ${ }^{13}$ Because BP relates strongly to height independently of age and sex,${ }^{19}$ the secular increases in children's height are likely to translate into partial increase in $\mathrm{BP}^{21}$ In this study, we observed that the height-adjusted BP levels decreased from 1985 to 2005, and increased between 2005 and 2010, despite the large rise in BMI and obesity.

Studies in the USA showed that childhood BP trends were downward from 1963 to 1988, with the prevalence of elevated BP declining markedly from $37.2 \%$ to $2.7 \%$, and upward to $3.7 \%$ in 1999 to $2002 .{ }^{9}$ That study suggested that a time lag of approximately 10 years may exist between the rise in obesity and the rise in $\mathrm{BP}^{9}$ However, other studies demonstrated that BP rapidly changes in response to weight change at the individual level. For instance, a meta-analysis revealed that obesity intervention significantly decreased BPs in 1 or 2 years. ${ }^{22}$ Our study, consistent with the findings in other populations, ${ }^{11}$ 23-25 also presented a quasilinear relationship between $\mathrm{BP}$ and BMI categories, which argues against a threshold in the relation between BMI and BP in children.
Our study also found that further adjustment of BMI cannot change BP trends. Previous studies evaluated that only $12-44 \%$ of the change in BP trends could be explained by the variation in BMI. ${ }^{9} 2026$ Thus, BMI alone may be unable to fully explain the trends in BP. Other latent factors, including birth weight, sodium intake, nutrition and physical activity, may help to explain the BP trends. Although we did not obtain birth weights in this study, mean birth weight has increased over the last decades in China, which could relate to improved maternal nutrition and favourable changes in socioeconomic factors. ${ }^{27}{ }^{28}$ Increasing birth weight may have accounted for some of the downward trends in BP. $^{29}$ Another national survey in Chinese adults showed that sodium intake decreased from $6.6 \mathrm{~g} /$ day in 1991 to $4.7 \mathrm{~g} /$ day in $2009 .^{30}$ Although it is still double the amount recommended by the WHO and by the Food and Agriculture Organization (FAO), ${ }^{31}$ a modest reduction in sodium intake may cause a fall in $\mathrm{BP}^{32}$

However, several risk factors of hypertension, besides obesity, also exist concurrently, which may contribute to the important recent rise in BP levels. Zhai et $a l^{33}$ investigated the change in dietary pattern among Chinese residents over the past three decades. That study found the nutrition transition dominated by a high intake of fat 
and animal food. On the contrary, the energy expenditure declined by $42 \%$ and $28 \%$ in Chinese boys and girls, respectively, between 1990 and $2005 .{ }^{12}$ Only $9.4 \%$ and $1.9 \%$ of urban Chinese boys and girls, respectively, met the recommendation of $60 \mathrm{~min} /$ day of moderate-to-vigorous physical activity in 2011 and 2012. ${ }^{34}$ In addition to these hypertensive risk factors, the recent downward trend in age of smoking initiation, as well as age of puberty, may also have impact on BP levels in Chinese children. ${ }^{45-37}$ The mechanisms at stake remain highly speculative. Since the recent increase in BP levels was persistent even after adjustment of BMI, our results suggested that studies on other determinants of elevated BP, including dietary behaviour, physical activity and smoking, are needed to provide further evidence.

Furthermore, to investigate whether the inconsistent trends in BP and BMI were related to the change of the strength of the BMI to BP association, the survey year-by-BMI category interaction terms were assessed in this study. Although some studies suggested that the association between BMI and BP is becoming weaker, ${ }^{8} 38$ little evidence was found to support this possibility. The survey year-by-BMI category interaction terms in our regression models presented inconsistent slight differences in the relationship of BP to BMI categories, which have also been reported elsewhere. ${ }^{611}$

The strengths of this study include the fact that it investigated the secular trends in BP in children based on a large sample size across a 25-year period. Additionally, the consistent stratified cluster sampling procedure and methods of systolic BP measurement contributed to the comparability of the data of different years. Our study also has some limitations. First, the BP was based on three measurements in a single visit, which may overestimate the BP levels, ${ }^{39}$ and multiple measurements are needed to make a clinical diagnosis of hypertension. ${ }^{19}$ However, the same methods of BP, especially systolic BP, measurement were employed over the entire period, and this is unlikely to change the BP trends. Second, there are limitations when using BP criteria developed on American children. ${ }^{40}$ However, the trends in mean BP and BP z-score were similar to those for elevated $B P$. In addition, the effect of cluster sampling was not taken into account in our analyses, because the information of the cluster variable (school) in 1985 was unavailable. Nonetheless, using the data between 1995 and 2010, taking multistage sampling into consideration, only led to slight changes in the results, which did not alter our conclusions. Furthermore, because only Han students were analysed, our results may not be generalisable to other populations.

In this study, BMI was employed to indicate adiposity. However, BMI is an indirect measure of overweight and less useful in determining the pathophysiological association with elevated $\mathrm{BP}^{41}$ Other more direct measures, including dual energy X-ray absorptiometry scan and MRI, can provide more accuracy association between obesity and BP. Moreover, some studies suggested that the site of fat deposition, such as an ectopic location, may have more important pathophysiological links to elevated BP than quality of adiposity alone. ${ }^{42}$ Unfortunately, these measures are resource intensive and cannot be determined from the design of our survey with such a large sample size. Although not perfect, a crucial relationship does exist between increasing BMI and rising levels of BP in this group, ${ }^{43}$ and repeated measurements of BMI over time were helpful to monitor the impact of obesity on elevated BP burden.

Finally, we cannot evaluate the latent influence of the unmeasured variables in these surveys, including birth weight, dietary behaviour and physical activity. However, this limitation does not minimise the importance of this study. Our study observed the recent increase in BP after a long period of decline using the large national data in Chinese school-age children for the first time. Because this is the beginning of a rise in BP, strong action taken now may prevent the progress of such a trend, and contribute to the potential reduction in adulthood hypertension and associated mortality in the future.

\section{CONCLUSIONS}

After declining for 20 years, BP levels in Chinese children started to climb upward. These trends in BP were inconsistent with the observation that BMI dramatically rose across the 25 years. Also, adjustment of BMI cannot change these BP trends. Our study indicated that there have been large variations in factors, which have counter-balanced the expected rise in BPs in recent years. In view of the essentially detrimental consequences of elevated BP in childhood on adulthood health, ${ }^{3}{ }^{44}$ it is urgent to further investigate the secular changes in other risk and preventive factors of elevated BP to improve cardiovascular health outcomes in the Chinese population.

Acknowledgements The authors would like to thank Wen-Ke Liao, Wen-Hua Xing, Xin Zhang and the members of the Chinese National Survey on Students' Constitution and Health (CNSSCH), for providing access to the survey data. They appreciate the helpful comments from Luke Arnold and Tania Pan, and are grateful for the cooperation of the students who participated in the survey.

Contributors BD conceptualised and designed the study, and drafted the initial manuscript. ZW and YS designed the study, carried out the initial analyses, and reviewed and revised the manuscript. JM and H-JW designed the data collection instruments, coordinated and supervised data collection, carried out the analyses and critically reviewed the manuscript. All the authors approved the final manuscript as submitted.

Funding This work was supported by the grant from National Health and Medical Research Council of Australia (number APP1045000) awarded to ZW.

Competing interests None declared.

Patient consent Obtained.

Ethics approval Medical Research Ethics Committee of the University of Queensland.

Provenance and peer review Not commissioned; externally peer reviewed.

Data sharing statement No additional data are available. 
Open Access This is an Open Access article distributed in accordance with the Creative Commons Attribution Non Commercial (CC BY-NC 4.0) license, which permits others to distribute, remix, adapt, build upon this work noncommercially, and license their derivative works on different terms, provided the original work is properly cited and the use is non-commercial. See: http:// creativecommons.org/licenses/by-nc/4.0/

\section{REFERENCES}

1. WHO. Global health risks: mortality and burden of disease attributable to selected major risks. Geneva: World Health Organization, 2009

2. Chiolero A, Bovet P, Paradis G. Screening for elevated blood pressure in children and adolescents: a critical appraisal. JAMA Pediatr 2013;167:266-73.

3. Chen X, Wang Y. Tracking of blood pressure from childhood to adulthood: a systematic review and meta-regression analysis. Circulation 2008;117:3171-80.

4. Daniels SR, Pratt CA, Hayman LL. Reduction of risk for cardiovascular disease in children and adolescents. Circulation 2011;124:1673-86.

5. Rahmouni K. Obesity-associated hypertension recent progress in deciphering the pathogenesis. Hypertension 2014;64:215-21.

6. Freedman DS, Goodman A, Contreras OA, et al. Secular trends in $\mathrm{BMI}$ and blood pressure among children and adolescents: the Bogalusa Heart Study. Pediatrics 2012;130:E159-66.

7. Shirasawa T, Ochiai $\mathrm{H}$, Nishimura R, et al. Secular trends in blood pressure among Japanese school children: a population-based annual survey from 1994 to 2010. J Epidemiol 2012;22:448-53.

8. Peters $\mathrm{H}$, Whincup $\mathrm{PH}$, Cook DG, et al. Trends in blood pressure in 9 to 11-year-old children in the United Kingdom 1980-2008: the impact of obesity. J Hypertens 2012;30:1708-17.

9. Din-Dzietham R, Liu Y, Bielo MV, et al. High blood pressure trends in children and adolescents in national surveys, 1963 to 2002. Circulation 2007;116:1488-96.

10. Khang YH, Lynch JW. Exploring determinants of secular decreases in childhood blood pressure and hypertension. Circulation 2011;124:397-405.

11. Chiolero A, Paradis G, Madeleine G, et al. Discordant secular trends in elevated blood pressure and obesity in children and adolescents in a rapidly developing country. Circulation 2009;119:558-65.

12. Ji CY, Chen TJ. Empirical changes in the prevalence of overweight and obesity among Chinese students from 1985 to 2010 and corresponding preventive strategies. Biomed Environ Sci 2013;26:1-12.

13. Liang $\mathrm{YJ}, \mathrm{Xi} \mathrm{B}, \mathrm{Hu} \mathrm{YH}$, et al. Trends in blood pressure and hypertension among Chinese children and adolescents: China Health and Nutrition Surveys 1991-2004. Blood Press 2010;20:45-53.

14. Chiolero A, Bovet $P$, Paradis $G$, et al. Has blood pressure increased in children in response to the obesity epidemic? Pediatrics 2007;119:544-53.

15. Ji CY, Chen TJ. Secular changes in stature and body mass index for Chinese youth in sixteen major cities, 1950s-2005. Am J Hum Biol 2008;20:530-7.

16. Cole TJ, Bellizzi MC, Flegal KM, et al. Establishing a standard definition for child overweight and obesity worldwide: international survey. BMJ 2000;320:1240.

17. Cole TJ, Flegal KM, Nicholls D, et al. Body mass index cut offs to define thinness in children and adolescents: international survey. BMJ 2007;335:194.

18. Kuczmarski RJ, Ogden CL, Guo SS, et al. 2000 CDC Growth Charts for the United States: methods and development. Vital Health Stat 11 2002;1-190.

19. National High Blood Pressure Education Program Working Group on High Blood Pressure in Children and Adolescents. The fourth report on the diagnosis, evaluation, and treatment of high blood pressure in children and adolescents. Pediatrics 2004;114(2 Suppl 4th Report):555-76.

20. Muntner $\mathrm{P}, \mathrm{He} \mathrm{J}$, Cutler JA, et al. Trends in blood pressure among children and adolescents. JAMA 2004;291:2107-13.
21. Luepker RV, Jacobs DR, Prineas RJ, et al. Secular trends of blood pressure and body size in a multi-ethnic adolescent population: 1986 to 1996 . J Pediatr 1999;134:668-74.

22. Ho M, Garnett SP, Baur L, et al. Effectiveness of lifestyle interventions in child obesity: systematic review with meta-analysis. Pediatrics 2012;130:e1647-71.

23. Abdulle A, Al-Junaibi A, Nagelkerke N. High blood pressure and its association with body weight among children and adolescents in the United Arab Emirates. PLOS ONE 2014;9:e85129.

24. Shirasawa $\mathrm{T}$, Shimada N, Ochiai $\mathrm{H}$, et al. High blood pressure in obese and nonobese Japanese children: blood pressure measurement is necessary even in nonobese Japanese children. $J$ Epidemiol 2010;20:408-12.

25. Freedman DS, Kahn HS, Mei Z, et al. Relation of body mass index and waist-to-height ratio to cardiovascular disease risk factors in children and adolescents: the Bogalusa Heart Study. Am J Clin Nutr 2007;86:33-40.

26. Dong $\mathrm{B}$, Wang $\mathrm{HJ}$, Wang $\mathrm{Z}$, et al. Trends in blood pressure and body mass index among Chinese children and adolescents from 2005 to 2010. Am J Hypertens 2013;26:997-1004.

27. Dai L, Deng C, Li Y, et al. Birth weight reference percentiles for Chinese. PLOS ONE 2014;9:e104779.

28. Shan X, Chen F, Wang W, et al. Secular trends of low birthweight and macrosomia and related maternal factors in Beijing, China: a longitudinal trend analysis. BMC Pregnancy Childbirth 2014; 14:105.

29. Chiolero A, Paradis G, Kaufman JS. Assessing the possible direct effect of birth weight on childhood blood pressure: a sensitivity analysis. Am J Epidemiol 2014;179:4-11.

30. Du S, Batis $\mathrm{C}$, Wang $\mathrm{H}$, et al. Understanding the patterns and trends of sodium intake, potassium intake, and sodium to potassium ratio and their effect on hypertension in China. Am J Clin Nutr 2014;99:334-43.

31. Nishida C, Uauy R, Kumanyika S, et al. The Joint WHO/FAO Expert Consultation on diet, nutrition and the prevention of chronic diseases: process, product and policy implications. Public Health Nutr 2004;7:245-50.

32. He FJ, MacGregor GA. Importance of salt in determining blood pressure in children: meta-analysis of controlled trials. Hypertension 2006;48:861-9.

33. Zhai $\mathrm{F}$, Wang $\mathrm{H}$, Du S, et al. Prospective study on nutrition transition in China. Nutr Rev 2009;67:S56-61.

34. Wang C, Chen PJ, Zhuang J. A national survey of physical activity and sedentary behavior of Chinese city children and youth using accelerometers. Res Q Exercise Sport 2013;84:S12-28.

35. Prentice P, Viner RM. Pubertal timing and adult obesity and cardiometabolic risk in women and men: a systematic review and meta-analysis. Int J Obes (Lond) 2013;37:1036-43.

36. Song $\mathrm{Y}, \mathrm{Ma} \mathrm{J}$, Wang $\mathrm{H}-\mathrm{J}$, et al. Trends of age at menarche and association with body mass index in Chinese school-aged girls, 1985-2010. J Pediatr 2014;165:1172-77.e1

37. Yang G, Fan L, Tan J, et al. Smoking in China: findings of the 1996 National Prevalence Survey. JAMA 1999:282:1247-53.

38. Danon-Hersch N, Chiolero A, Shamlaye C, et al. Decreasing association between body mass index and blood pressure over time. Epidemiology 2007;18:493-500.

39. McNiece KL, Poffenbarger TS, Turner JL, et al. Prevalence of hypertension and pre-hypertension among adolescents. J Pediatr 2007;150:640-4.

40. Jafar $\mathrm{TH}$, Islam M, Poulter N, et al. Children in South Asia have higher body mass-adjusted blood pressure levels than white children in the United States: a comparative study. Circulation 2005;111:1291-7.

41. Tchernof A, Després JP. Pathophysiology of human visceral obesity: an update. Physiol Rev 2013;93:359-404.

42. Lim S, Meigs JB. Links between ectopic fat and vascular disease in humans. Arterioscl Throm Vas 2014:34:1820-6.

43. Friedemann $\mathrm{C}$, Heneghan $\mathrm{C}$, Mahtani $\mathrm{K}$, et al. Cardiovascular disease risk in healthy children and its association with body mass index: systematic review and meta-analysis. BMJ 2012;345:e4759.

44. Sundstrom J, Neovius M, Tynelius $P$, et al. Association of blood pressure in late adolescence with subsequent mortality: cohort study of Swedish male conscripts. BMJ 2011;342:d643. 